\title{
CyPPA, a positive SK3/SK2 modulator, reduces activity of dopaminergic neurons, inhibits dopamine release, and counteracts hyperdopaminergic behaviors induced by methylphenidate ${ }^{1}$
}

\author{
Kjartan F. Herrik ${ }^{1}$, John P. Redrobe ${ }^{1}$, Dorte Holst ${ }^{2}$, Charlotte Hougaard ${ }^{2}$, Karin Sandager-Nielsen ${ }^{2}$, \\ Alexander N. Nielsen ${ }^{2}$, Huifang Ji ${ }^{3}$, Nina M. Holst ${ }^{4}$, Hanne B. Rasmussen ${ }^{4}$, Elsebet Ø. Nielsen ${ }^{2}$, \\ Dorte Strøbæk ${ }^{2}$, Paul D. Shepard ${ }^{3}$ and Palle Christophersen ${ }^{2}$
}

${ }^{1}$ H. Lundbeck A/S, Valby, Denmark

${ }^{2}$ NeuroSearch A/S, Ballerup, Denmark

${ }^{3}$ Department of Psychiatry, Maryland Psychiatric Research Center, University of Maryland School of Medicine, Baltimore, MD, USA

${ }^{4}$ Department of Biomedical Sciences, Faculty of Health Sciences, The Panum Institute, University of Copenhagen, Copenhagen, Denmark

\section{Edited by:}

Amalia M. Dolga, Philipps-Universität Marburg, Germany

Reviewed by:

Enrico Sanna, University of Cagliari, Italy

Jason B. Wu, Cedars-Sinai Medical Center, USA

*Correspondence:

Palle Christophersen, NeuroSearch A/S, Pederstrupvej 93, DK2750

Ballerup, Denmark.

e-mail:pc@neurosearch.com

${ }^{1}$ The authors would like to acknowledge the scientific and mentoring contributions provided by our deceased colleague, Dr. Huifang $\mathrm{Ji}$, in the completion of this manuscript. Part of this work has been published previously in abstract form (FENS abstr., Vol. 4, 078.13, 2008).
Dopamine (DA) containing midbrain neurons play critical roles in several psychiatric and neurological diseases, including schizophrenia and attention deficit hyperactivity disorder, and the substantia nigra pars compacta neurons selectively degenerate in Parkinson's disease. Pharmacological modulation of DA receptors and transporters are well established approaches for treatment of DA-related disorders. Direct modulation of the DA system by influencing the discharge pattern of these autonomously firing neurons has yet to be exploited as a potential therapeutic strategy. Small conductance $\mathrm{Ca}^{2+}$-activated $\mathrm{K}^{+}$channels (SK channels), in particular the SK3 subtype, are important in the physiology of DA neurons, and agents modifying SK channel activity could potentially affect DA signaling and DA-related behaviors. Here we show that cyclohexyl-[2-(3,5-dimethyl-pyrazol-1-yl)-6methyl-pyrimidin-4-yl]-amine (CyPPA), a subtype-selective positive modulator of SK channels (SK3 > SK2 > > > SK1, IK), decreased spontaneous firing rate, increased the duration of the apamin-sensitive afterhyperpolarization, and caused an activity-dependent inhibition of current-evoked action potentials in DA neurons from both mouse and rat midbrain slices. Using an immunocytochemically and pharmacologically validated DA release assay employing cultured DA neurons from rats, we show that CyPPA repressed DA release in a concentration-dependent manner with a maximal effect equal to the D2 receptor agonist quinpirole. In vivo studies revealed that systemic administration of CyPPA attenuated methylphenidate-induced hyperactivity and stereotypic behaviors in mice. Taken together, the data accentuate the important role played by SK3 channels in the physiology of DA neurons, and indicate that their facilitation by CyPPA profoundly influences physiological as well as pharmacologically induced hyperdopaminergic behavior.

Keywords: substantia nigra compacta, dopamine release, immunocytochemistry, mAHP, apamin, NS8593, $\mathrm{K}_{\mathrm{ca}}{ }^{2}$ KCNN

\section{INTRODUCTION}

Small conductance $\mathrm{Ca}^{2+}$-activated $\mathrm{K}^{+}$channels (SK channels, $\mathrm{K}_{\mathrm{Ca}} 2$, encoded by $K C N N$ genes) are widely distributed in the central nervous system, with the SK1 and SK2 subtypes expressed mainly in cortical/limbic areas and SK3 mostly in the striatum, habenula, and in the monoaminergic nuclei (Sailer et al., 2004;

\footnotetext{
Abbreviations: aCSF, artificial cerebrospinal fluid; AP, action potential; CyPPA, cyclohexyl-[2-(3,5-dimethyl-pyrazol-1-yl)-6-methyl-pyrimidin-4-yl]-amine; DA, dopamine; ECL, enhanced chemiluminescence; i.p., intraperitoneal; mAHP, medium duration afterhyperpolarization; NS8593, $(R)-N$-(benzimidazol-2-yl)1,2,3,4-tetrahydro-1-naphtylamine; $\mathrm{SK}$, small conductance $\mathrm{Ca}^{2+}$ activated $\mathrm{K}^{+}$conductance; s.c., subcutaneous; SNc, substantia nigra pars compacta; $\mathrm{TH}$, tyrosine hydroxylase.
}

Sarpal et al., 2004). SK channels are voltage-insensitive $\mathrm{K}^{+}$channels activated exclusively by a rise in the intracellular $\mathrm{Ca}^{2+}$ concentration (Köhler et al., 1996) and, owing to their functional coupling to $\mathrm{Ca}^{2+}$ influx sources, SK channels serve as important feedback regulators of $\mathrm{Ca}^{2+}$ signaling in neurons. SK channels expressed in the soma control excitability and firing patterns by generating a $\mathrm{Ca}^{2+}$-dependent afterhyperpolarization of medium duration (mAHP) after single spikes or trains of action potentials, whereas SK-mediated hyperpolarization of dendritic spines following excitatory input accelerates $\mathrm{Mg}^{2+}$ block of NMDA receptors and thus contributes to synaptic plasticity in the hippocampus (Stocker, 2004; Hammond et al., 2006). In dopaminergic (DA) neurons of the substantia nigra pars compacta ( $\mathrm{SNc}$ ), cyclic activation of SK3 channels is important for timing and stability of the slow 
endogenous pacemaker activity exhibited by these neurons (Wolfart et al., 2001), and SK inhibitors induce irregular or even burst firing (Shepard and Bunney, 1988; Johnson and Wu, 2004; Waroux et al., 2005; Ji and Shepard, 2006; Ji et al., 2009; Herrik et al., 2010).

The relationship between firing rate and firing pattern of DA neurons versus the intensity and quality of DA signaling in their target areas, including the striatum and cortex, has long been debated. A current belief is that DA exerts two main actions: a tonic, far reaching influence caused by regularly firing DA neurons slowly releasing DA from sites weakly influenced by DA uptake such as varicosities and dendrites; and a phasic influence governed by synchronized burst firing, mediating a synaptic DA transmission temporally and spatially restricted by the activity of the DA transporter (Grace, 1991). Physiologically, burst firing/phasic DA release is elicited by unexpected reward and is thought to represent a positive learning signal for goal-directed behaviors (Schultz, 2007). Recently, a unifying mathematical model of DA neuron firing, release, uptake, and receptor activation confirmed that synchronized bursting can be the mechanism that modulates the balance between activation of D1 and D2 receptors (Dreyer et al., 2010). A disturbed balance between tonic and phasic DA transmission has been proposed to underlie some DA-related disorders, including schizophrenia, attention deficit hyperactivity disorder (ADHD), and melancholic depression (Grace et al., 2007), and may also play a role in addiction, in particular toward alcohol (Hopf et al., 2011). Emerging evidence also suggest increased bursting of DA neurons in Parkinson's disease (Bishop et al., 2010).

The importance of the SK3 channel in regulating the firing pattern of DA neurons makes it a possible target for therapeutic intervention in DA-related disorders. The structural and functional similarity between SK channel isoforms suggest that subtype selectivity may be difficult to obtain and present a potential obstacle for drug development at this target (Wulff et al., 2007). Another challenge is the translations from actions on the cloned channel to the physiology of DA neurons, and the eventual influence on DA transmission and behavior.

We have attempted to address some of these questions using cyclohexyl-[2-(3,5-dimethyl-pyrazol-1-yl)-6-methylpyrimidin-4-yl]-amine (CyPPA; Hougaard et al., 2007), the first subtype-selective positive gating modulator of SK3 channels (SK3 $>$ SK2 $>>>$ SK1,IK). Our results show that CyPPA strongly reduces activity and excitability of DA neurons in slices, inhibits the spontaneous release of DA from cultured DA neurons expressing SK3, and is capable of inhibiting hyperactivity and stereotypic behaviors induced by methylphenidate in vivo.

\section{MATERIALS AND METHODS ANIMAL ETHICS AND PERMISSIONS}

Procedures involving animals for the preparation of brain slices and cell cultures were conducted in strict accordance with the guidelines described in the Guide for Care and Use of Laboratory Animals, the policies adopted by the Society for Neuroscience, and the Danish Committee for Experiments on Animals. For the behavioral studies, all testing procedures were in accordance with the "Guide for the Care and Use of Laboratory Animals" (2011) and the Danish Animal Experimentation Act.

\section{CHEMICALS AND REAGENTS}

CyPPA and NS8593 were synthesized at NeuroSearch A/S, Ballerup, Denmark (Strøbæk et al., 2006; Hougaard et al., 2007). For the in vitro experiments, CyPPA and NS8593 were prepared as a $10 \mathrm{mM}$ stock solution in dimethylsulfoxide (DMSO) and stored in aliquots at $-20^{\circ} \mathrm{C}$. The final concentration of DMSO in the experimental solutions was $\leq 0.1 \%$, a concentration which had no effect on the activity of DA neurons in slices or on the release of ${ }^{3} \mathrm{H}$-DA from cell cultures. For the in vivo experiments, CyPPA was freshly dissolved in a 5\% cremophor/glucose solution $1 \mathrm{~h}$ before testing. Methylphenidate hydrochloride (SigmaAldrich, Copenhagen, Denmark) was freshly dissolved in a 5\% glucose solution $1 \mathrm{~h}$ before testing. CyPPA was administered intraperitoneally (i.p.) and methylphenidate was given via the subcutaneous (s.c.) route in injection volumes of $10 \mathrm{ml} / \mathrm{kg}$. Apamin was purchased from Sigma-Aldrich (Copenhagen, Denmark) and stored as a stock solution in acetic acid (0.01\%). Trypsin, DNAse, penicillin/streptomycin, poly-L-lysin, glutamine, pargyline, ascorbate, cytosine arabinoside, and Dulbecco's phosphate buffered saline (PBS) were all purchased from SigmaAldrich (Copenhagen, Denmark). Neurobasal media and B-27 were obtained from Invitrogen (Nærum, Denmark) and ${ }^{3} \mathrm{H}$ DA was acquired from PerkinElmer Life and Analytical Sciences (Boston, MA, USA)

The primary antibodies used were a rabbit polyclonal antiSK3 antibody (1:100, APC-025) from Alomone Labs (Jerusalem, Israel) and a monoclonal mouse anti-tyrosine hydroxylase antibody (1:150, clone LNC1) from Millipore (Copenhagen, Denmark). Secondary antibodies used were Alexa Fluor ${ }^{\otimes} 488$ goat anti-mouse $\operatorname{IgG}(1: 800)$ and Alexa Fluor ${ }^{\circledast} 568$ goat anti-rabbit IgG (1:800) purchased from Invitrogen (Nærum, Denmark). ProLong ${ }^{\circledast}$ Gold antifade reagent was obtained from Invitrogen (Nærum, Denmark). Paraformaldehyde was acquired from Ampliqon (Skovlunde, Denmark). All inorganic salts were purchased from commercial dealers and of the purest grade available.

\section{MIDBRAIN SLICES}

C57BL/6J mice (9-15 post-natal days old, Charles River, Wilmington, MA, USA) or Sprague-Dawley rats (10-13 post-natal days old, Taconic, Ry, Denmark) were used for experiments. The animals were sacrificed by decapitation and the brains were rapidly removed and placed in ice-cold modified artificial cerebrospinal fluid (aCSF) consisting of (in mM): $124 \mathrm{NaCl}, 4 \mathrm{KCl}, 1.25$ $\mathrm{NaH}_{2} \mathrm{PO}_{4}, 1.2 \mathrm{MgSO}_{4}, 25.7 \mathrm{NaHCO}_{3}, 2.45 \mathrm{CaCl}_{2}, 0.15$ ascorbate, and 11 glucose bubbled with $95 \% \mathrm{O}_{2}$ plus $5 \% \mathrm{CO}_{2}(\mathrm{pH} 7.35$, $295-305 \mathrm{mOsm}$ ). Coronal sections ( 250 or $300 \mu \mathrm{m}$ ) containing the $\mathrm{SNc}$ were prepared using a vibrating tissue slicer (WPI, Sarasota, FL, USA) or (Leica VT1200, Ballerup, Denmark), transferred to a custom incubation chamber, and submerged in aCSF at room temperature for a minimum of $1 \mathrm{~h}$. Individual slices were subsequently transferred to the recording chamber and superfused $(1.5 \mathrm{ml} / \mathrm{min})$ with oxygenated aCSF at $30^{\circ} \mathrm{C}$. 


\section{ELECTROPHYSIOLOGY}

Whole-cell patch-clamp recordings were made from putative DA neurons in the SNc visualized using an Olympus BX51WI microscope equipped with a CCD camera (OLY-150IR). Borosilicate patch pipettes were filled with a solution containing (in $\mathrm{mM}$ ): 131 K-gluconate, $9 \mathrm{KCl}, 20 \mathrm{HEPES}, 0.1 \mathrm{EGTA}, 5 \mathrm{Mg}$-ATP, and 0.5 GTP TRIS (pH 7.2, osmolarity 280-290 mOsm, resistance $18-20 \mathrm{M} \Omega$, mouse slices) or $135 \mathrm{~K}$-gluconate, $10 \mathrm{KCl}, 10 \mathrm{HEPES}, 1 \mathrm{MgCl}_{2}$, 5 Mg-ATP, and 0.5 Na-GTP (pH 7.2, osmolarity 280-290 mOsm, resistance $8-10 \mathrm{M} \Omega$, rat slices). Current clamp recordings were performed using an Axoclamp 2B (Molecular Devices, Sunnyvale, CA, USA) or an EPC9 (HEKA, Lambrecht, Germany) amplifier. Experimental control, data acquisition, and basic analyses were done with the pCLAMP 10 (Molecular Devices) or Patchmaster (HEKA) software packages. Input resistance was estimated by measuring the change in membrane voltage produced by rectangular current pulses of sufficient duration $(250 \mathrm{~ms})$ to fully charge the membrane capacitance. In experiments involving current pulse injections, cells were hyperpolarized slightly in order to suppress spontaneous spiking during measurements. Compounds were applied to the superfusate by exchanging the aCSF for a solution that differed only by the addition of a known concentration of test compounds.

\section{PREPARATION OF MIDBRAIN NEURON CULTURES}

To obtain enough tissue for the release assay, DA neurons were cultured from rats. The ventral part of the mesencephalon of prenatal Sprague-Dawley pups (e14; Taconic; Gl. Ry, Denmark) was dissected under 10 times magnification. The tissues were placed in a HEPES buffered saline (HIB) containing (in $\mathrm{mM}$ ): $129 \mathrm{NaCl}, 5 \mathrm{KCl}, 25$ HEPES, 9.1 glucose, 0.04 phenol red $(\mathrm{pH}$ 7.4), and roughly split by forceps. After mild trypsination $(0.2 \%$ trypsin and $40 \mu \mathrm{g} / \mathrm{ml}$ DNAse at $37^{\circ} \mathrm{C}$ for $15 \mathrm{~min}$ ) the tissue was centrifuged to remove enzymes and re-suspended in Neurobasal media supplemented with $10 \%$ fetal calf serum and B-27, $2 \mathrm{mM}$ glutamine, penicillin/streptomycin $(0.5 \mathrm{U} / \mathrm{ml} / 0.5 \mu \mathrm{g} / \mathrm{ml})$, and further disaggregated by repeated mechanical trituration using a steel needle and a disposable syringe. The cells were plated at a final density of $0.5 \times 10^{6} \mathrm{cells} / \mathrm{ml}$ on poly-L-lysine $(10 \mu \mathrm{g} / \mathrm{ml})$ coated cover slips for immunohistochemistry, and 48 well culture plates (NUNC, Denmark) for the release assay. Cells were maintained in culture for $7-8$ days in $5 \% \mathrm{CO}_{2} / 95 \% \mathrm{O}_{2}$ at $37^{\circ} \mathrm{C}$. After 2 days culturing, the media was changed to serum free media with addition of $5 \mu \mathrm{M}$ cytosine arabinoside. Under these conditions, glial proliferation was reduced to less than $2 \%$ of the total cell number.

\section{IMMUNOCYTOCHEMISTRY, CONFOCAL MICROSCOPY, AND IMAGING}

Cultured rat midbrain neurons (8 days in vitro), grown on glass cover slips, were fixed with $2 \%$ paraformaldehyde in Dulbecco's PBS (pH 7.4) for $15 \mathrm{~min}$ at room temperature. Quenching was performed by $30 \mathrm{~min}$ incubation with $0.1 \%$ Triton X-100/4\% lowfat milk powder in a wash buffer containing $(\mathrm{mM}): 100$ Tris HCL (pH 7.5) and $150 \mathrm{NaCl}$. The cells were then incubated for $1 \mathrm{~h}$ with primary antibody diluted in wash buffer. Secondary antibodies were diluted in wash buffer and applied for $45 \mathrm{~min}$. After washing the labeled cells were mounted in ProLong ${ }^{\circledR}$ Gold antifade reagent.
Laser scanning confocal microscopy was performed using the Leica TCS SP2 system equipped with argon and helium-neon lasers. The objective was $63 \mathrm{X} \mathrm{W}, \mathrm{NA} 1.2$. Sequential scanning was employed to allow separation of signals from the channels. The obtained images were processed using Adobe Photoshop ${ }^{\circledR}$ CS2 version 9.0.2.

\section{HEK293 CELL CULTURE AND TRANSFECTIONS}

HEK 293 cells were grown in DMEM supplemented with $100 \mathrm{U} / \mathrm{ml}$ penicillin, $100 \mathrm{mg} / \mathrm{ml}$ streptomycin, and $10 \%$ FCS at $37^{\circ} \mathrm{C}$ in a humidified atmosphere with $5 \% \mathrm{CO}_{2}$. The cells were transiently transfected with rat SK1, SK2, or SK3 in pXOOM (Peitersen et al., 2006) using the Lipofectamine-Plus Reagent system (Invitrogen, Nærum, Denmark). Two days after transfection, the cells were scraped in ice-cold PBS and pelleted at $1000 \mathrm{rpm}$ for $2 \mathrm{~min}$. The cell pellet was re-suspended in SDS sample buffer [ $2 \%(\mathrm{w} / \mathrm{v})$ SDS, $5 \%$ $(\mathrm{v} / \mathrm{v}) \beta$-mercaptoethanol, $0.02 \%(\mathrm{w} / \mathrm{v})$ bromophenol blue, $10 \%$ $(\mathrm{v} / \mathrm{v})$ glycerol, $12.5 \%(\mathrm{v} / \mathrm{v})$ stacking gel buffer] and kept at $-80^{\circ} \mathrm{C}$ until use.

\section{WESTERN BLOTTING}

Purified rat brain membranes (RBM; $30 \mu \mathrm{g} / \mathrm{lane}$ ), total lysates of midbrain neuron cultures and lysates from HEK293 cells expressing rSK1, rSK2, or rSK3 were separated on 4-15\% SDS-PAGE polyacrylamide gels using the Bio-Rad Laboratories minigel system (Hercules, CA, USA). Proteins were transferred onto a HybondP PVDF transfer membrane (Amersham Biosciences, $0.45 \mu \mathrm{m}$ ) in $25 \mathrm{mM}$ Tris base, $200 \mathrm{mM}$ glycine, $20 \%$ methanol using a mini transblot (Hercules, CA, USA). After transfer, the membranes were incubated for $1 \mathrm{~h}$ at room temperature in blocking buffer (PBS containing 4\% low-fat milk powder). The membrane was incubated overnight at room temperature in blocking buffer containing anti-SK3 antibody (1:300 dilution). Bound antibody was revealed with HRP-conjugated donkey anti-rabbit antibody (1:10000, Jackson immunoresearch Laboratories, West grove, PA, USA) in blocking buffer for $45 \mathrm{~min}$, followed by visualization with a homemade ECL solution. Immunoblots were exposed on hyperfilm ECL (Amersham Biosciences, Brøndby, Denmark).

\section{DOPAMINE RELEASE}

Cultured rat brain neurons were incubated for $45 \mathrm{~min}(5 \%$ $\mathrm{CO}_{2} / 95 \% \mathrm{O}_{2}$ at $37^{\circ} \mathrm{C}$ ) in a buffered salt solution containing (in $\mathrm{mM}): 120 \mathrm{NaCl}, 5 \mathrm{KCl}, 1,2 \mathrm{CaCl}_{2}, 1.2 \mathrm{MgSO}_{4}, 1$ ascorbic acid, 5 glucose, pargyline ( $40 \mathrm{mg} / \mathrm{l} ; \mathrm{pH}$ 7.4) supplied with $50 \mathrm{nM}^{3} \mathrm{H}-\mathrm{DA}$, and then washed three times at room temperature. After addition of $200 \mu \mathrm{l}$ buffer for $5 \mathrm{~min}$ at $37^{\circ} \mathrm{C}, 200 \mu \mathrm{l}$ was sampled and counted (Tri-Carb 2800TR, Perkin Elmer) for estimation of basal DA release $(B)$. Stimulated release $(S)$ was performed by increasing the $\mathrm{KCl}$ concentration to $25 \mathrm{mM}$ (1:1 exchange with $\mathrm{NaCl}$ ) or inclusion of the pharmacological agents in question. Finally, the cells were lysed by addition of $200 \mu \mathrm{l}$ SDS (1\%) for $1 \mathrm{~h}$, and thereafter collected and counted $(L)$. The relative release was calculated as the difference between the fraction of stimulated release and the fraction of basal release (Anderson et al., 2009) after the following formula:

Relative release $=\left(\frac{S}{S+L}\right)-\left(\frac{B}{B+S+L}\right)$ 


\section{BEHAVIORAL STUDIES}

Female NMRI mice (24-26g) obtained from Taconic (Ry, Denmark) were used for behavioral testing. After arrival, mice were allowed a minimum of 7 days acclimatization prior to testing. The subjects were housed eight per cage in Makrolon III cages $(20 \mathrm{~cm} \times 40 \mathrm{~cm} \times 18 \mathrm{~cm})$, with food and water available ad libitum on a $12 / 12 \mathrm{~h}$ light/dark cycle with lights-on at 6 am. All cages were enclosed within a Scantainer (Scanbur A/S, Køge, Denmark). Group housing and isolation from males were chosen to prolong estrus above the normal 4-5 days (Ma et al., 1999), and to promote synchronous cycling (Koyama, 2004). Experiments were performed between 9:00 and 16:00 $\mathrm{h}$ in temperature and humidity-regulated rooms $\left(22-24^{\circ} \mathrm{C}\right.$, relative humidity: $\left.60-70 \%\right)$, and each animal was used only once.

Exploratory activity was evaluated in test cages $(20 \mathrm{~cm} \times 40 \mathrm{~cm}$ $\times 18 \mathrm{~cm}$, TSE Systems, Bad Homburg, Germany) equipped with infrared sensors $(6 \times 2)$ for automatic acquisition of animal movements. Mice were individually placed in cages, and locomotor activity was recorded via interruption of infrared sensor pairs and processed on a computer (ActiMot software, TSE Systems, Bad Homburg, Germany). The testing period was set to $30 \mathrm{~min}$ in order to reveal the effect of compound on active exploratory locomotor activity. Mice were injected with CyPPA or vehicle $15 \mathrm{~min}$ before testing.

Methylphenidate-induced hyperactivity was assessed by using the same apparatus as described for the exploratory activity experiments. Mice were injected (i.p.) with vehicle or CyPPA $15 \mathrm{~min}$ before administration of methylphenidate $(2.5 \mathrm{mg} / \mathrm{kg}$ or saline, s.c.) and locomotor activity was recorded immediately thereafter. A 60 min test period was chosen since the effects of methylphenidate on motility are of slow onset and peak at approximately $30 \mathrm{~min}$ following s.c. administration.

In a separate group of experiments, methylphenidateinduced stereotypic behavior was induced by administration of methylphenidate $(40 \mathrm{mg} / \mathrm{kg}$ or saline, s.c.), $15 \mathrm{~min}$ after the mice were treated with CyPPA or vehicle (i.p.). Animals were then placed in transparent Makrolon cages $(25 \mathrm{~cm} \times 30 \mathrm{~cm} \times 12 \mathrm{~cm})$, fitted with a corrugated cardboard floor. The degree of stereotypic gnawing of the corrugated cardboard floor was scored after $60 \mathrm{~min}$ (rating scale: $0-6 ; 0=$ absence of gnawing; 6: pronounced gnawing of the cardboard floor) by a trained observer blinded to the treatment groups.

\section{STATISTICAL ANALYSES}

Data are presented given as means \pm SEM. Significance testing was performed using Student's $t$-test, paired $t$-tests, or two-way analysis of variance (ANOVA) followed by Tukey or Holm Sidak multiple comparison tests, as appropriate. Data were considered statistically significant when $P<0.05$.

\section{RESULTS \\ MIDBRAIN SLICE ELECTROPHYSIOLOGY}

CyPPA is a positive gating modulator that concentrationdependently increases the apparent $\mathrm{Ca}^{2+}$-sensitivity of recombinant SK3 channels $\left(\mathrm{EC}_{50}=5 \mu \mathrm{M}\right)$, and to a lesser degree SK2 channels $\left(\mathrm{EC}_{50}=13 \mu \mathrm{M}\right)$, with limited effect on SK1 and IK channels (Hougaard et al., 2007). However, the compound also inhibits $\mathrm{Na}_{\mathrm{v}}$ channel currents from rat dorsal root ganglion neurons at slightly higher concentrations $\left(\mathrm{IC}_{50}=11 \mu \mathrm{M}\right)$. In order to elucidate which was the predominant effect on DA neurons we performed current clamp recordings from visually identified SNc DA neurons in midbrain slices. DA neurons were selected on the basis of well established characteristics including size, shape, presence of spontaneous activity, and a hyperpolarization-induced depolarizing current, $I_{\mathrm{h}}$, mediating a pronounced "sag" response. We first explored the effect of CyPPA in slices from C57BL/6J mice. The DA neurons exhibited a spontaneous, slow $(1.9 \pm 0.5 \mathrm{~Hz}$, $n=16)$ pacemaker discharge characterized by broad action potentials ( $>2.5$ ms measured at $1 / 2$ AP amplitude) separated by deep afterhyperpolarizations (AHP), and slowly ramping depolarizations leading to the next spike, as illustrated in Figure 1A (black trace). Application of CyPPA, at a concentration of $10 \mu \mathrm{M}$, quickly slowed the firing frequency and eventually silenced the neuron completely (blue trace). Co-application with the negative gating modulator NS8593, which decreases the apparent $\mathrm{Ca}^{2+}$-sensitivity of SK channels, (green trace) reestablished regular spontaneous pace-making at a slightly lower frequency than the control situation. Subsequent abolishment of all SK channel activity, by adding the SK channel blocker apamin $(300 \mathrm{nM})$, resulted in irregular firing at somewhat higher frequency (red trace). The effect of CyPPA on the spontaneous firing was concentration-dependent and Figure 1B shows the concentration-response curve compiled from a series of independent experiments. An $\mathrm{EC}_{50}$ around $2 \mu \mathrm{M}$ is inferred from this curve. The effect on evoked isolated AP's is shown in Figure 1C. Examples were obtained before and during application of $10 \mu \mathrm{M}$ CyPPA, after co-application with NS8593, and after further addition of apamin. CyPPA caused a pronounced increase in the duration of the MAHP, whereas the AHP amplitude was less affected. Co-application with NS8593 just blunted the CyPPA effect, whereas apamin completely abolished the SKmediated component of the AHP, again showing limited effect on the early peak AHP. Note that both inhibitors spared the fAHP immediately following the AP. As shown in the Appendix (Figure A1 in Appendix), very similar effects of CyPPA and apamin were obtained with rat DA neurons, securing that a possible species variation in the basic pharmacology of DA neurons is not an issue.

The effects of increased SK channel activation on DA neurons exposed to an increased excitatory drive, were studied by eliciting trains of action potentials by current injections of varying durations (200 or $800 \mathrm{~ms}$ ) and intensities (0.05-0.5 nA). We investigated the effects on the spike frequency adaptation at the plateau depolarization, as well as the effect on the post train AHP (ptAHP). Figure 2 (left trace) illustrates the typical response of a DA neuron to a $0.5 \mathrm{nA}, 200 \mathrm{~ms}$ stimulation eliciting a train of four spikes with increasing $\mathrm{mAHPs}$, increasing interspike intervals, and a pronounced ptAHP. Application of CyPPA $(10 \mu \mathrm{M})$ abolished all spikes, except the initial one and prolonged the ptAHP. During co-application of CyPPA and apamin (300 nM), the spike trains returned, now without visible mAHPs or increasing interspike intervals, and only with a very slowly developing ptAHP (middle trace) that was not present after single AP's. The compiled experiments are analyzed in Figure 3. For both the short and long depolarizing pulses, the number of evoked spikes 
A

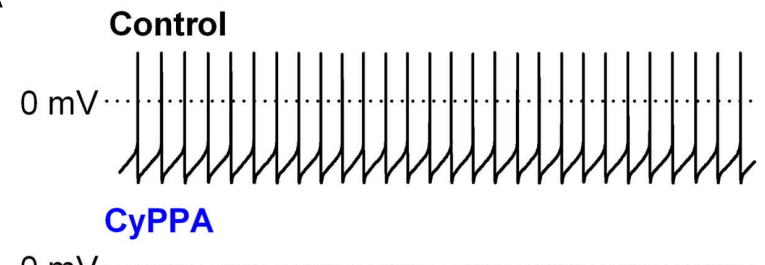

$0 \mathrm{mV}$

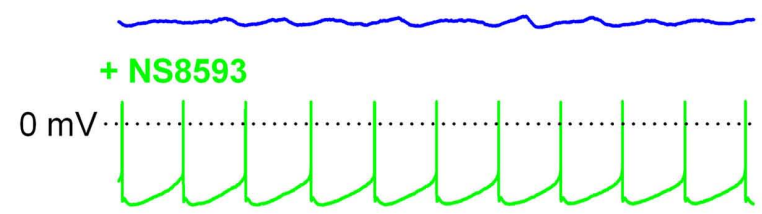

+ Apamin

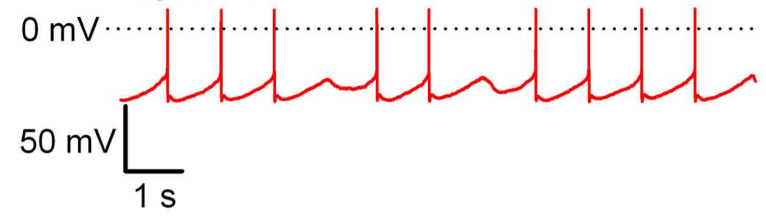

B

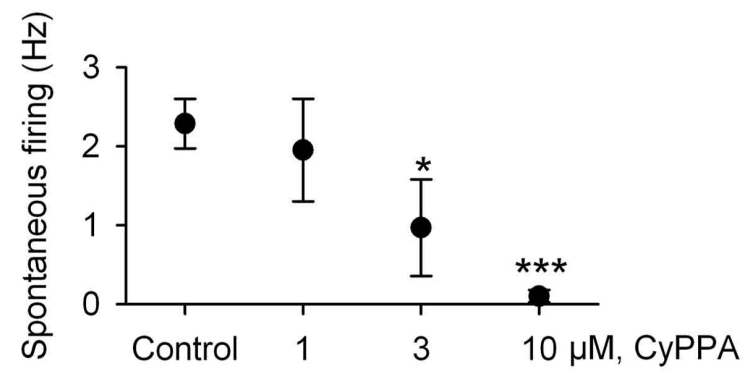

C

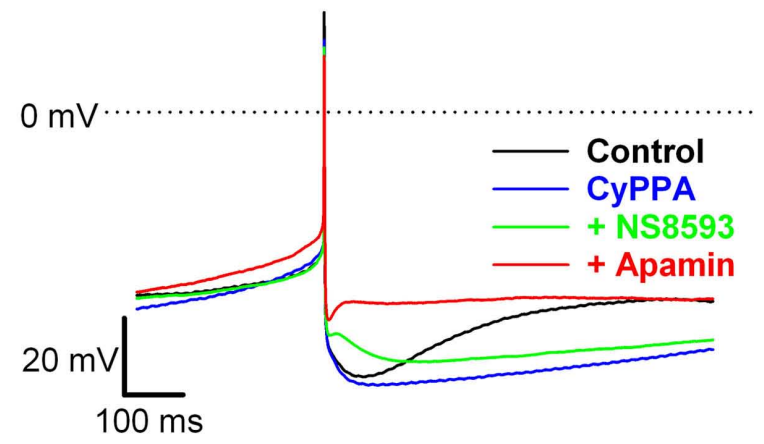

FIGURE 1 | CyPPA inhibits spontaneous activity via. prolongation of the apamin-sensitive medium afterhyperpolarization (mAHP) in SNc DA neurons in mice midbrain slices. (A) Typical pacemaker-like activity (black trace), is inhibited by superfusion with $10 \mu \mathrm{M}$ CyPPA (blue trace), which increases mAHPs and eventually silences firing activity.

Co-administration with $10 \mu \mathrm{M}$ NS8593 resumes pacemaker firing (green trace), whereas apamin $(300 \mathrm{nM})$ caused a slightly further increase in firing frequency and more irregular firing. (B) Concentration-response curve of spontaneous firing activity before and after CyPPA superfusion (control, 1 , $3,10 \mu \mathrm{M}, n=7,2,3$, and 5 respectively. One-way ANOVA followed by Holm Sidak multiple comparison test. ${ }^{*} P<0.05$ and $\left.{ }^{* *} P<0.001\right)$. (C) Overlain single spikes before and after CyPPA $(10 \mu \mathrm{M}), \mathrm{CyPPA}+\mathrm{NS} 8593(10 \mu \mathrm{M})$, and CyPPA + NS8593 + apamin (300 nM). Color coding as in (A). Note the prolongation of the MAHP by CyPPA, which is reduced by NS8593, and completely blocked by apamin. increased with the current intensity and decreased with increasing concentrations of CyPPA (Figures 3A,B, left). The inhibitory effects of CyPPA on AP generation were more pronounced the higher the stimulation intensity and the longer the stimulation duration. At the highest current intensities and $10 \mu \mathrm{M}$ CyPPA the effects were significant in both short and long pulse experiments [200 ms, $0.5 \mathrm{nA}: F(3,21)=4.19 ; P=0.018$ and $800 \mathrm{~ms}, 0.2 \mathrm{nA}$; $F(3,15)=3.54 ; P=0.041$, respectively). The effects of $10 \mu \mathrm{M}$ CyPPA on amplitude and duration of ptAHP are shown in the middle and right panels of Figure 3. CyPPA increased the ptAHP peak amplitude by approximately 1.3 and 1.6 fold, respectively $(200 \mathrm{~ms}$ : $\left.t_{4}=-2.797, P=0.049 ; 800 \mathrm{~ms}: t_{2}=-4.507, P=0.046\right)$. СуPРA even more pronouncedly increased the duration of the ptAHP (3.5 and 2 fold, quantified as the $50 \%$ decay time from the peak value) in both the short and the long pulse experiments $(200 \mathrm{~ms}, 0.5 \mathrm{nA}$ : $\left.t_{4}=-4.702 ; P=0.009 ; 800 \mathrm{~ms}, 0.2 \mathrm{nA}: t_{2}=-4.3427 ; P=0.047\right)$.

We also explored the ability of CyPPA to revert bursting of DA neurons experimentally induced by NS8593 (see Discussion for context). Figure 4 shows a typical example of NS8593-induced bursting characterized by long plateau depolarizations with accelerating AP activity suddenly interrupted by strong hyperpolarizations, which may well correspond to the non SK-mediated ptAHP activated by strong depolarizations (Figure 2). Co-application of $10 \mu \mathrm{M}$ CyPPA occluded this conductance and caused pacemaker rhythmicity to be reestablished at a slightly lower activity level than observed before application of NS8593.

In summary, the prevailing effect of CyPPA on DA neurons from both rat and mice SNc, is decreased spontaneous firing, increased duration of the $\mathrm{mAHP}$, causing spike frequency adaptation, and a prolonged ptAHP following long depolarizing stimuli; all effects clearly attributable to positive modulation of apaminsensitive SK channels. The ability of CyPPA to revert the effect of a negative SK channel modulator further strengthens this conclusion. The slight depression of AP heights in some experiments with $10 \mu \mathrm{M}$ CyPPA, for example the co-application experiment with NS8593, may well reflect a slight $\mathrm{Na}_{\mathrm{v}}$ channel block under these conditions.

\section{DOPAMINE RELEASE FROM CULTURED MIDBRAIN NEURONS}

In order to verify the effect of the altered excitability/firing pattern, and to determine its consequences on release of DA from nerve terminals/dendrites, we established and validated a DA release assay based on a primary culture of neurons derived from rat embryonic midbrain. On average, $10 \%$ of the neurons in the culture were tyrosine hydroxylase (TH) positive (results not shown), and were identified as DA neurons. To examine whether SK3 was expressed in these cultures, Western blot analysis using an SK3 specific antibody was performed. A band of approximately $70 \mathrm{kDa}$ was detected in midbrain culture lysates documenting expression of SK3 in the cultures. A band of similar size was observed in RBM lysates and HEK293 cells transfected with rSK3, but was absent in HEK293 cells transfected with rSK1 and rSK2, demonstrating specificity of the SK3 antibody (Figure 5A). To demonstrate preserved expression of SK3 in identified cultured DA neurons, we performed co-immunostainings with antibodies directed against SK3 and TH (Figure 5B). TH+ neurons displayed SK3 immunoreactivity with the densest SK3 staining associated with the soma, 
$\underline{\mathbf{A}}$
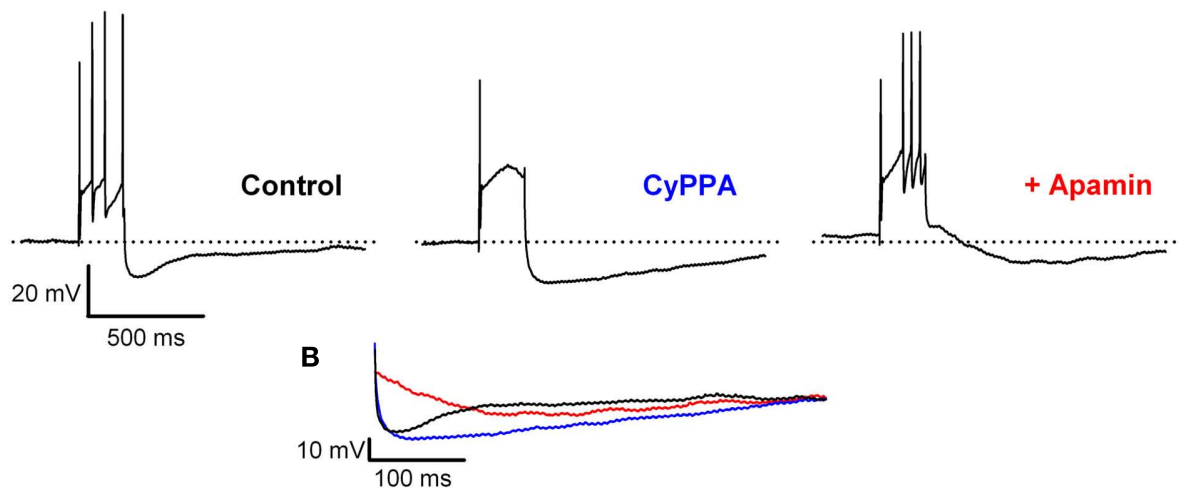

FIGURE 2 | CyPPA inhibits evoked spike trains and prolongates the post train afterhyperpolarizations (ptAHP) in midbrain slices from mice. (A) Representative spike trains evoked by a $200 \mathrm{~ms}, 0.5 \mathrm{nA}$ current injection under control conditions (left), after $10 \mu \mathrm{M}$ CyPPA (middle), and with co-application of $300 \mathrm{nM}$ apamin (right). The dotted line indicates the $V_{\mathrm{m}}$ $(-56 \mathrm{mV})$ prior to first control current injection. (B) Overlays highlighting the prolongation of the ptAHP by CyPPA, and the presence of a slow apamin insensitive component.

\section{A}

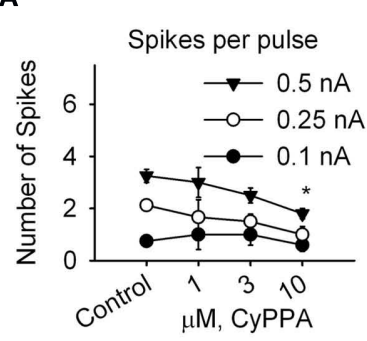

B

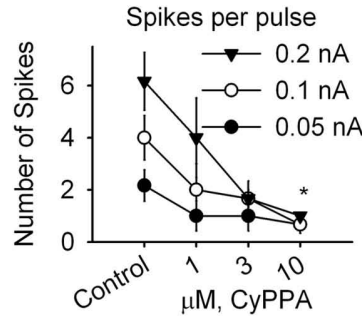

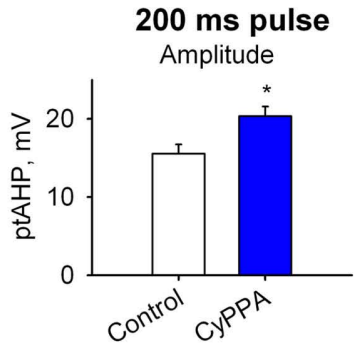

$800 \mathrm{~ms}$ pulse

Amplitude

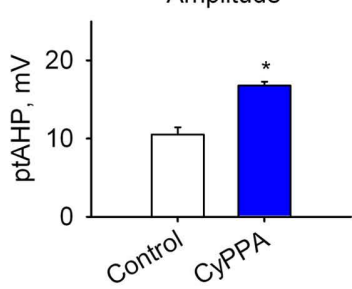

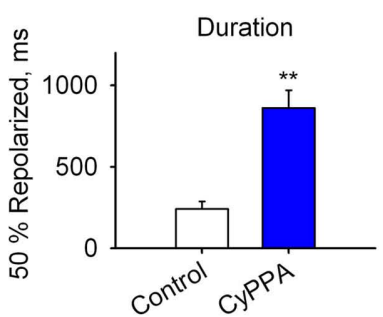

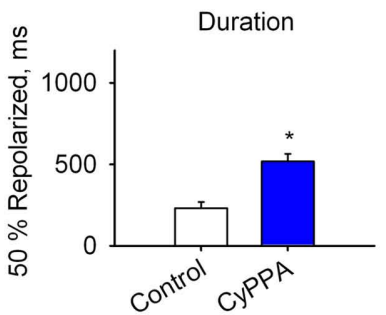

FIGURE 3 | Summary of the effects of current pulse intensity [(A): $200 \mathrm{~ms} ; 0.1,0.25,0.5 \mathrm{nA}$; (B): $800 \mathrm{~ms} ; 0.05,0.1,0.2 \mathrm{nA}$ ] and CyPPA concentrations $(1,3$, and $10 \mu \mathrm{M})$ on DA neuron activity, ptAHP-amplitude, and -duration. The number of spikes decrease concentration-dependently most obviously at the longer pulses, reflecting the significance of increasing mAHP $(n=8,3,4,5,200$ ms pulse; $n=6,3,3,3$, $800 \mathrm{~ms}$ pulse). Middle panels, peak amplitude of ptAHP compared with baseline membrane potential $\left(V_{m}\right)$ before and after $10 \mu \mathrm{M}$ CyPPA $(n=3)$. Right panels, time for $50 \%$ repolarization from peak of ptAHP to baseline $V_{m}$ before and after $10 \mu \mathrm{M}$ CyPPA $(n=3) .{ }^{*} P<0.05$ and ${ }^{*} P<0.01$. where clustered as well as diffuse, possibly intracellular, staining was observed. The dendrites also revealed a clustered staining pattern in contrast to the axons of $\mathrm{TH}+$ neurons where very little SK3 immunoreactivity was detected. Some staining for SK2 was also observed in the culture, but no consistent expression of SK2 was associated with $\mathrm{TH}+$ neurons (data not shown).

The cultured DA neurons were capable of accumulating ${ }^{3} \mathrm{H}$ DA, which could be inhibited by $1 \mu \mathrm{M}$ benztropine showing specific uptake mediated by the DA transporter (data not shown).
When the DA neurons were subsequently kept under standard conditions, a basal release of DA was observed probably due to preserved spontaneous firing of these neurons in culture. Depolarization of the membrane by increasing the extracellular $\mathrm{K}^{+}$ concentration to $25 \mathrm{mM}$ stimulated the DA release by 2.5 fold (Figure 5C). In contrast, TTX $(1 \mu \mathrm{M})$ or $\mathrm{Cd}^{2+}(30 \mu \mathrm{M})$ inhibited the spontaneous release showing that $\mathrm{Na}_{\mathrm{V}}$-dependent $\mathrm{AP}$ formation and $\mathrm{Ca}^{2+}$ influx are important. Figure 5D shows the effects of specific dopaminergic reference compounds. The 
cultures responded to the DA antagonist haloperidol $(3 \mu \mathrm{M})$ by a threefold stimulation of DA release, most likely indicating inhibition of a tonically active D2 auto-receptor, resulting in an

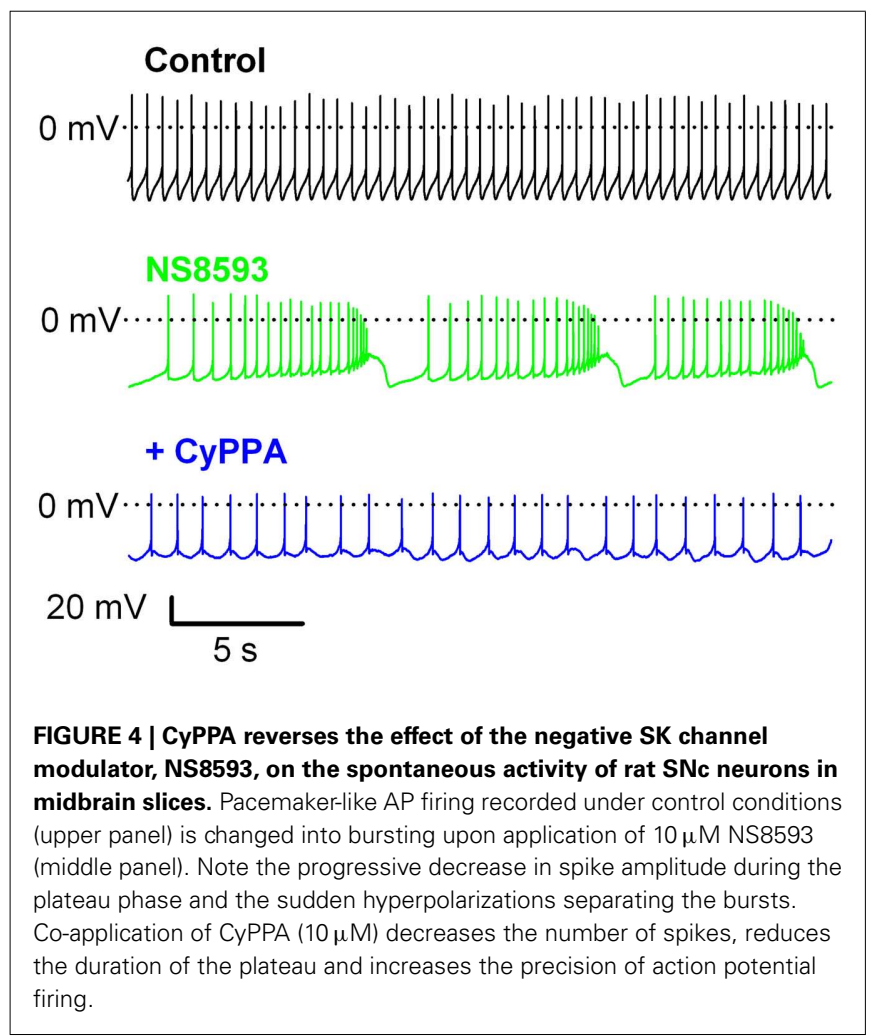

increase in firing rate and DA release. Consistently, addition of $10 \mu \mathrm{M}$ quinpirole, a D2 receptor agonist, repressed dopamine release. Figure 5D also shows the effect of increasing concentrations of CyPPA; at $3 \mu \mathrm{M}$ little effect was detected, whereas 10 and $30 \mu \mathrm{M}$ showed a significant inhibition of spontaneous DA release.

\section{BEHAVIORAL STUDIES}

In order to assess the effect of CyPPA on spontaneous exploratory locomotor activity, the compound was administered to otherwise un-treated NMRI mice exposed to a novel environment (see Materials and Methods for details). As shown in Figure 6A, CyPPA significantly reduced the total activity level over the 30 min test session at a dose of $30 \mathrm{mg} / \mathrm{kg}[F(3,167)=31.5, P<0.001]$, but was devoid of effect at doses of 3 and $10 \mathrm{mg} / \mathrm{kg}$. To elucidate a possible increased effect of CyPPA in hyperactive animals, we also tested the compound in a methylphenidate-induced hyperactivity paradigm (Figure 6B). A relatively low dose of methylphenidate $(2.5 \mathrm{mg} / \mathrm{kg}$, s.c.) engendered a significant increase in activity over the $60 \mathrm{~min}$ test period $(P<0.001)$. Methylphenidate-induced hyperactivity was attenuated by pretreatment with CyPPA at doses of 10 and $30 \mathrm{mg} / \mathrm{kg}[F(4,407)=45.9, P<0.001$ for both], but was without significant effect at $3 \mathrm{mg} / \mathrm{kg}$. Finally, the effect of CyPPA on dopaminergic stereotypies was tested. As shown in Figure 7, a high dose of methylphenidate $(40 \mathrm{mg} / \mathrm{kg}$, s.c.) induced a significant increase in stereotypic behavior $(P<0.001)$ over the $60 \mathrm{~min}$ test period. Methylphenidate-induced stereotypic behavior was significantly reduced by CyPPA at doses of 10 and $30 \mathrm{mg} / \mathrm{kg}$ $[F(4,25)=13.67, P<0.05$ and $P<0.001$, respectively $]$, but was devoid of effect at $3 \mathrm{mg} / \mathrm{kg}$.

\section{A}

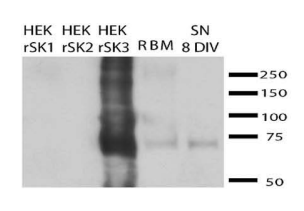

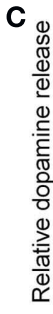

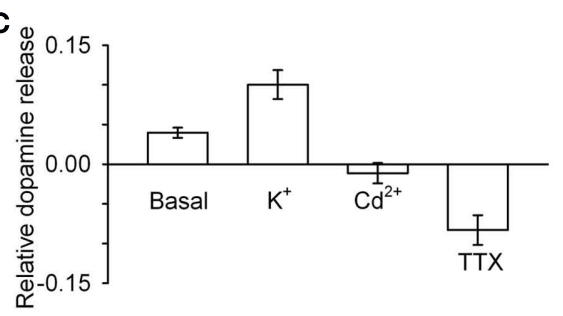

B
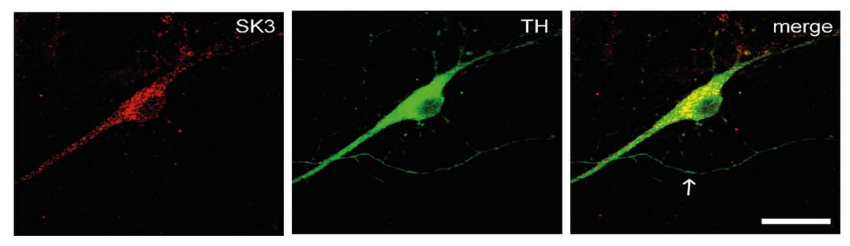

D

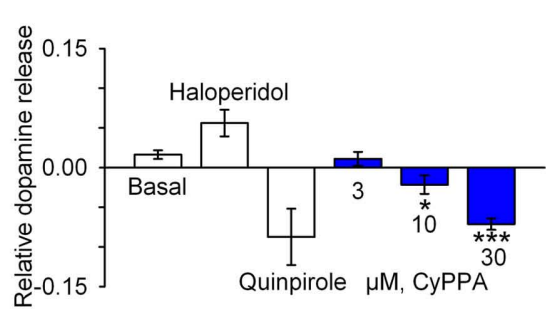

FIGURE 5 | CyPPA inhibits spontaneous and evoked release of dopamine form TH/SK3 positive cultured rat midbrain neurons. (A) Western blot detection of SK3 in rat midbrain cultures. Extracts of HEK293 cells transiently transfected with rSK1, rSK2, and rSK3 and adult rat brain membranes (RBM) as well as lysates from cultured midbrain neurons were separated on 4-15\% SDS-PAGE and immunoblotted with anti-SK3 antibody. A band of approximately $70 \mathrm{kDa}$ was detected in midbrain cultures, RBM lysates, and HEK293 cells transfected with rSK3. This band was absent in lanes loaded with HEK293 cells expressing rSK1 and rSK2. (B) Immunodetection of SK3 subunits in rat midbrain cultures. Cultured midbrain neurons (8 days in vitro) were double-labeled for SK3 and tyrosine hydroxylase (TH). In TH-positive dopaminergic neurons, the SK3 subunit displayed a primarily somatic-dendritic localization whereas little immunoreactivity was associated with axons (arrow). Scale bar $20 \mu \mathrm{m}$. (C) Basal release and stimulated release with $25 \mathrm{mM} \mathrm{KCl}$ or inhibited release with $30 \mu \mathrm{M} \mathrm{Cd}^{2+}$ and with $1 \mu \mathrm{MTTX}$ (D) Basal release and stimulated release with $3 \mu \mathrm{M}$ haloperidol and inhibited release with $10 \mu \mathrm{M}$ quinpirole. Blue bars represent inhibited release with increasing concentrations of CyPPA ( $\left.P<0.05,{ }^{*} P<0.01\right)$. The data presented are representative of three independent experiments. 


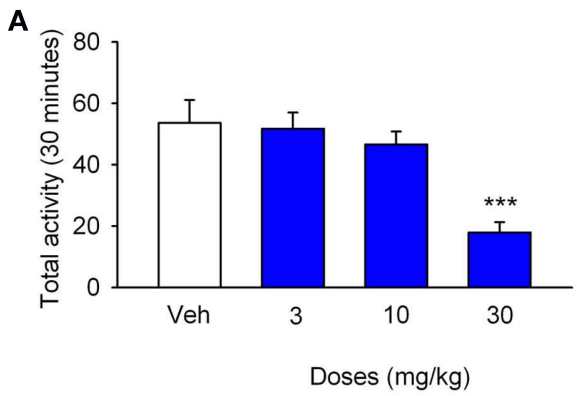

FIGURE 6 | CyPPA depresses explorative activity and methylphenidate-induced hyperactivity in mice. (A) Effect of CyPPA on basic explorative activity. Data are expressed as mean total distances traveled + SEM. Mice were injected with vehicle (i.p.; open bar) or CyPPA $(3,10$, and $30 \mathrm{mg} / \mathrm{kg}$, blue bars) $15 \mathrm{~min}$ before testing. ** $P<0.001$ versus vehicle treated group (two-way ANOVA followed by Tukey's multiple comparison test, $n=7$ ). (B) Effects of CyPPA on

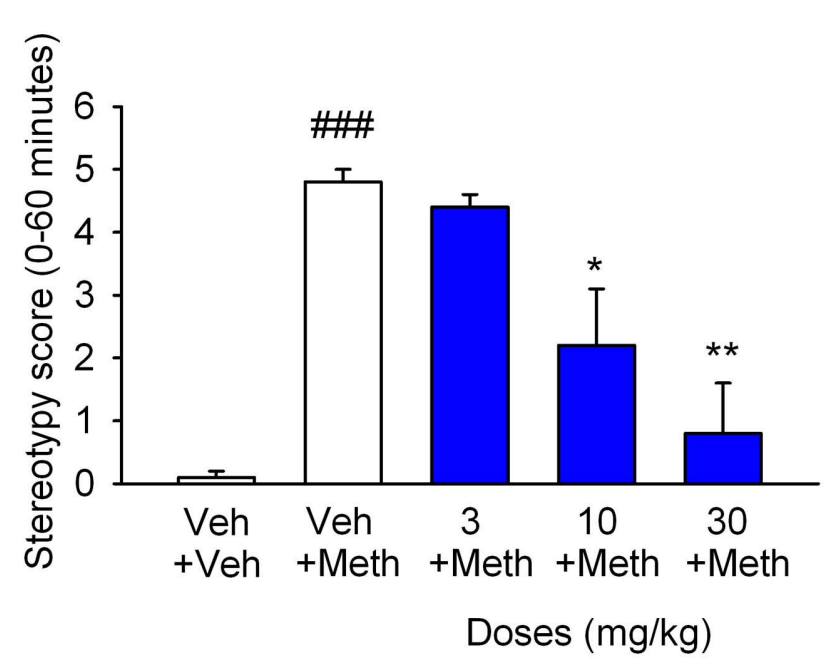

FIGURE 7 | CyPPA counteracts methylphenidate-induced stereotypies in mice. Effects of CyPPA on methylphenidate (METH)-induced stereotypy. Data are expressed as mean total gnawing score + SEM. Mice were dosed (i.p.) with vehicle or CyPPA (3, 10, and $30 \mathrm{mg} / \mathrm{kg}) 15 \mathrm{~min}$ before administration of METH (40 mg/kg, s.c.) or saline, respectively (blue bars). ${ }^{\# \# \# P} P<0.001$ versus vehicle treated group, ${ }^{*} P<0.05$, ${ }^{* *} P<0.001$ versus METH treated group (one-way ANOVA followed by Tukey's multiple comparison test, $n=6$ ).

\section{DISCUSSION}

This study addressed the effect of the SK3/SK2 selective positive modulator CyPPA on DA neurons from rats and mice. The combined results extend previous studies asserting the expression and critical role of SK3 channels in the physiology and pharmacology of these neurons (Wolfart et al., 2001; Sailer et al., 2004; Sarpal et al., 2004), since CyPPA-enhancement of the SK3 $\mathrm{Ca}^{2+}$-sensitivity altered firing properties and DA release from midbrain neurons, effects that most likely also explain the observed dampening of dopaminergic hyperactivity induced by methylphenidate.

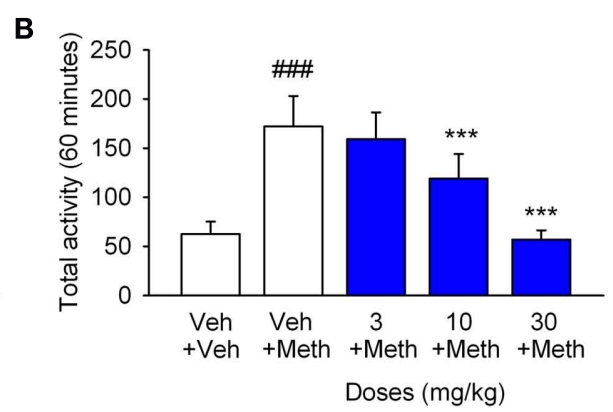

methylphenidate (METH)-induced hyperactivity. Data are expressed as mean total distances traveled + SEM. Mice were dosed (i.p.) with vehicle (open bar) or CyPPA (3, 10, and $30 \mathrm{mg} / \mathrm{kg}$ ) $15 \mathrm{~min}$ before administration of METH $(2.5 \mathrm{mg} / \mathrm{kg}$, s.c.) or saline, respectively (blue bars). ${ }^{\# \#} P<0.001$ versus vehicle treated group, ${ }^{* *} P<0.001$ versus METH treated group (two-way ANOVA followed by Tukey's multiple comparison test, $n=7$ ).

CyPPA concentration-dependently $\left(\mathrm{EC}_{50}=2 \mu \mathrm{M}\right)$ reduced the autonomous firing rate of DA neurons in coronal slices from both mice and rat midbrains, with an essentially full silencing at a concentration of $10 \mu \mathrm{M}$. Paying specific attention to the previously described off-target inhibition of $\mathrm{Na}_{\mathrm{V}}$-channels currents from rat dorsal root ganglion neurons, we document here, using several lines of evidence, that the dominating effect of CyPPA is attributable to SK3 channel facilitation. Firstly, cells silenced by CyPPA returned to a spontaneous firing mode upon co-superfusion with NS8593, a negative SK channel gating modulator, or apamin, a SK channel blocker. In addition, CyPPA prolonged both the duration of the MAHP following single autonomous - or evoked action potentials, as well as the ptAHP following trains of spikes elicited by constant current pulses of varying intensity, all in an apaminsensitive manner. These results converge with the finding that 1-EBIO, the prototype SK/IK channel activator, mainly slows the off-rate of $\mathrm{Ca}^{2+}$ from the SK channel, thereby extending the time the channel stays open upon a sudden $\mathrm{Ca}^{2+}$ removal (Pedarzani et al., 2001), a condition that mimics the local $\mathrm{Ca}^{2+}$-clearance following an action potential. Furthermore, CyPPA reduced the frequency of current-evoked APs in an activity-dependent manner (more effectively the higher the stimulation frequency), a modeof-operation closely mimicking the action of 1-EBIO and NS309, the unselective SK channel activators that have previously been characterized on DA neurons (Wolfart et al., 2001; Ji et al., 2009). Finally, in our analysis we also specifically exploited the fact that, in terms of mode-of-action, CyPPA behaves as a classic positive gating modulator of SK3 channels, including its mode-of-interaction with negative gating modulators (compounds that decrease the apparent $\mathrm{Ca}^{2+}$ affinity). As shown previously for NS309, the effect of CyPPA dominates the effect of a co-applied negative gating modulator (NS8593; Strøbæk et al., 2006; Ji et al., 2009; Jenkins et al., 2011). In the current context, we specifically showed that the firing pattern of a DA neuron being switched to stable bursting by addition of NS8593 was reverted to near normal pace-maker rhythmicity by co-applying CyPPA. Collectively, we therefore conclude that CyPPA's main effect on the firing pattern is via its potentiation of SK3 channel activity. 
The functional consequences of positive SK channel modulation on DA release was assessed using an 8 day midbrain neuronal culture that contained $\mathrm{TH}+$ neurons and which appeared to retain some level of spontaneous activity. These presumptive DA neurons expressed SK3 as validated by co-immunostaining for TH and SK3 proteins. This was supported by functional measurements showing specific (benztropine sensitive) ${ }^{3} \mathrm{H}$-DA uptake via the DA transporter and a continuous $\mathrm{Ca}^{2+}$-dependent and TTX/Cd ${ }^{2+}$-sensitive ${ }^{3} \mathrm{H}$-DA release from these neurons. We interpret this as the basal DA release from autonomously firing pace-making DA neurons, a firing mode previously described for isolated dopaminergic neurons (Puopolo et al., 2007). In accordance, imposing constant depolarizing conditions by addition of a higher $\mathrm{K}^{+}$-concentration accelerated the $\mathrm{TTX} / \mathrm{Cd}^{2+}$-sensitive release as expected. The DA neurons expressed functional D2 receptors as well, since the cultures responded to both the D2 receptor antagonist haloperidol with an increase in the ${ }^{3} \mathrm{H}$-DA release, while the $\mathrm{D} 2$ agonist quinpirole attenuated spontaneous DA release. These effects further imply correct coupling to Gprotein coupled potassium channels (GIRKs), since activation of D2 auto-receptors increases GIRK conductance, hyperpolarizes the cell membrane, and diminish the firing rate of the DA neuron. Conversely, by blocking the tonic inhibitory effects of endogenously released dopamine at DA auto-receptors, a likely outcome given the non-flow release assay used here, haloperidol would presumably have caused an increase in firing and a corresponding increase in DA release (Lacey et al., 1987; Pucak and Grace, 1996).

For comparison with conventional DA neuron pharmacology, we also tested the effect of CyPPA on the pharmacologically validated cultures. CyPPA clearly inhibited the autonomous ${ }^{3} \mathrm{H}-\mathrm{DA}$ release in a concentration-dependent manner $\left(\mathrm{EC}_{50} \sim 10 \mu \mathrm{M}\right)$ and the maximal concentration of $30 \mu \mathrm{M}$ was as efficacious as $10 \mu \mathrm{M}$ of the D2 agonist quinpirole. It is tempting to conclude that this effect is solely due to SK3 activation, but the effective concentrations are slightly higher than those used in the electrophysiological experiments and a contribution from the $\mathrm{Na}_{\mathrm{v}}$ channel inhibition cannot be ruled out. However, since relatively high concentrations of both haloperidol and quinpirole are also needed to obtain maximal efficacy (D2 receptor affinities in the nanomolar range), the release assay may uniformly be less sensitive to pharmacological interference.

Based on the observed effects in slices and neuronal cultures, we investigated whether CyPPA could attenuate classic hyperdopaminergic effects of psychostimulants in vivo. Methylphenidate blocks DA and norepinephrine (NE) reuptake transporters, causing an increase in extracellular levels of these neurotransmitters, but exerts a less potent effect on serotonin uptake (Kuczenski and Segal, 1997). Using in vivo single unit electrophysiology of DA neurons, methylphenidate, and other psychostimulants - have been shown to elicit complex electrophysiological responses, with both dampening and excitatory/burstinducing elements (Shi et al., 2004). Behaviorally, methylphenidate promotes a dose-dependent profile that typically manifests as hyperactivity at lower doses, and marked stereotypic behavior (including biting/gnawing, sniffing, licking) at higher doses (Randrup et al., 1988). Systemic administration of CyPPA was found both to diminish methylphenidate-induced hyperactivity and stereotypic behavior at doses that did not significantly affect exploratory activity. Although SK3 channels are also expressed on the NE-containing neurons in the locus coeruleus, the mechanisms underlying the observed behavioral changes in response to CyPPA are most likely due to a dampening of DA activity in the nucleus accumbens and in nigrostriatal and ventral tegmental regions thought to be critical for the expression of hyperactivity (Kelly and Iversen, 1976) and stereotypic behavior, respectively.

Since the founding description of CyPPA as a subtype-selective SK3/SK2 channel activator (Hougaard et al., 2007) only a few studies focusing on its effects in the DA system have been published. (Benítez et al., 2011) showed that the non-selective 1-EBIO as well as CyPPA, two chemically very disparate molecules, were able to counteract AMPA neurotoxicity on DA neurons in culture. The protective role of SK channels was further strengthened by showing that both the peptide blocker apamin and the small molecule negative modulator NS8593 accelerated the death of DA neurons. At the in vivo level it has been shown that locally applied 1-EBIO counteracted the loss of $\mathrm{TH}+$ neurons after 6-OHDA treatment, whereas apamin accelerated the loss (Aumann et al., 2008). Considering more broadly the possible role of SK channels in the protection of DA neurons, it is also worth noting a recent study (Bishop et al., 2010) showing that DA neurons from genetically altered mice being deficient in the Parkinson's disease "susceptibility genes" PINK1 and HtrA2/Omi exhibit increased excitability and bursting specifically due to down regulated SK3 channel expression or activity. Thus, positive SK3 channel modulation may not only acutely affect DA neuron hyperactivity as demonstrated here, but it may also exert longer lasting neuroprotective effects on these cells.

It is worth noting that the idea of neuroprotection via SK channel facilitation is not necessarily limited to DA neurons. Using cortical neurons, it has recently been shown that NS309 was able to counteract excitotoxic $\mathrm{Ca}^{2+}$ signaling induced by glutamate or NMDA, and that NS309 could reduce the ischemic damage in vivo following occlusion of the middle cerebral artery (Dolga et al., 2011). In support of SK2 channels being coexpressed and functionally coupled with NMDA receptors in dendritic spines, a recent study furthermore concluded (Allen et al., 2011) that 1-EBIO was neuroprotective as well, most likely by strengthening of the negative feedback of SK2 channel activation on NMDA receptors. Given the important role of NMDA receptors in hippocampus-mediated learning and memory processes, it may not be surprising that both CyPPA and 1-EBIO (Vick et al., 2010) have been reported to impair memory encoding. The conclusion is that the SK3/SK2 selectivity ratio of only 2.5 as demonstrated for CyPPA (Hougaard et al., 2007 ) is probably too small to obtain a pure stimulation of SK3dependent processes in the brain. A preferable therapeutic drug for DA-related disorders should therefore probably be a molecule even further optimized in the direction of higher SK3/SK2 selectivity.

\section{ACKNOWLEDGMENTS}

Susanne K. Hansen and Anne B. Fisher are greatly acknowledged for help with preparation of midbrain slices (SKH) and 
the dopamine release experiments (SKH, ABF). Camilla Bramlev and Gitte Sørensen are acknowledged for help with the testing in

\section{REFERENCES}

Allen, D., Nakayama, S., Kuroiwa, M., Nakano, T., Palmateer, J., Kosaka, Y., Ballesteros, C., Watanabe, M., Bond, C. T., Luján, R., Maylie, J., Adelman, J. P., and Herson, P. S. (2011). SK2 channels are neuroprotective for ischemia-induced neuronal cell death. J. Cereb. Blood Flow Metab. 31, 2302-2312.

Anderson, D. J., Malysz, J., Grønlien, J. H., El Kouhen, R., Håkerud, M., Wetterstrand, C., Briggs, C. A., and Gopalakrishnan, M. (2009). Stimulation of dopamine release by nicotinic acetylcholine receptor ligands in rat brain slices correlates with the profile of high, but not low, sensitivity $\alpha 4 \beta 2$ subunit combination. Biochem. Pharmacol. 78, 844-851.

Aumann, T. D., Gantois, I., Egan, K., Vais, A., Tomas, D., Drago, J., and Horne, M. K. (2008). SK channel function regulates the dopamine phenotype of neurons in the substantia nigra pars compacta. Exp. Neurol. 213, 419-430.

Benítez, B. A., Belálcazar, H. M., Anastasía, A., Mamah, D. T., Zorumski, C. F., Mascó, D. H., Herrera, D. G., and de Erausquin, G. A. (2011). Functional reduction of SK3-mediated currents precedes AMPA-receptormediated excitotoxicity in dopaminergic neurons. Neuropharmacology 60, 1176-1186.

Bishop, M. W., Chakraborty, S., Matthews, G. A., Dougalis, A., Wood, N. W., Festenstein, R., and Ungless, M. A. (2010). Hyperexcitable substantia nigra dopamine neurons in PINK1- and HtrA2/Omideficient mice. J. Neurophysiol. 104, 3009-3020.

Dolga, A. M., Terpolilli, N., Kepura, F., Nijholt, I. M., Knaus, H. G., D’Orsi, B., Prehn, J. H., Eisel, U. L., Plant, T., Plesnila, N., and Culmsee, C. (2011). $\mathrm{KCa} 2$ channels activation prevents $\left[\mathrm{Ca}^{2+}\right]$ i deregulation and reduces neuronal death following glutamate toxicity and cerebral ischemia. Cell Death Dis. 2, e147.

Dreyer, J. K., Herrik, K. F., Berg, R. W., and Hounsgaard, J. D. (2010). Influence of phasic and tonic dopamine release on receptor activation. J. Neurosci. 30, 14273-14283.

Grace, A. A. (1991). Phasic versus tonic dopamine release and the modulation of dopamine system responsivity: a hypothesis for the etiology of schizophrenia. Neuroscience 41, $1-24$.
Grace, A. A., Floresco, S. B., Goto, Y., and Lodge, D. J. (2007). Regulation of firing of dopaminergic neurons and control of goal-directed behaviors. Trends Neurosci. 30, 220-227.

Hammond, R. S., Bond, C. T., Strassmaier, T., Ngo-Anh, T. J., Adelman, J. P., Maylie, J., and Stackman, R. W. activated $\mathrm{K}^{+}$channel type 2 (SK2) modulates hippocampal learning, memory, and synaptic plasticity. $J$. Neurosci. 26, 1844-1853.

Herrik, K. F., Christophersen, P., and Shepard, P. D. (2010). Pharmacological modulation of the gating properties of small conductance $\mathrm{Ca}^{2+}$ activated $\mathrm{K}^{+}$channels alters the firing pattern of dopamine neurons in vivo. J. Neurophysiol. 104, 1726-1735.

Hopf, F. W., Seif, T., and Bonci, A. (2011). The SK channel as a novel target for treating alcohol use disorders. Channels 5, 289-292.

Hougaard, C., Eriksen, B. L., Jørgensen, S., Johansen, T. H., Dyhring, T., Madsen, L. S., Strøbæk, D., and Christophersen, P. (2007). Selective positive modulation of the SK3 and SK2 subtypes of small conductance $\mathrm{Ca}^{2+}$-activated $\mathrm{K}^{+}$channels. $\mathrm{Br}$. J. Pharmacol. 151, 655-665.

Jenkins, D. P., Strøbæk, D., Hougaard, C., Jensen, M. L., Hummel, R., Sørensen, U. S., Christophersen, P., and Wulff, H. (2011). Negative gating modulation by (R)- $N$-(benzimidazol-2-yl)-1,2,3,4tetrahydro-1-naphthylamine

(NS8593) depends on residues in the inner pore vestibule: pharmacological evidence of deep-pore gating of $\mathrm{K}(\mathrm{Ca}) 2$ channels. Mol. Pharmacol. 79, 899-909.

Ji, H., Hougaard, C., Herrik, K. F., Strøbæk, D., Christophersen, P., and Shepard, P. D. (2009). Tuning the excitability of midbrain dopamine neurons by modulating the $\mathrm{Ca}^{2+}$ sensitivity of SK channels. Eur. J. Neurosci. 29, 1883-1895.

Ji, H., and Shepard, P. D. (2006). SK $\mathrm{Ca}^{2+}$-activated $\mathrm{K}^{+}$channel ligands alter the firing pattern of dopaminecontaining neurons in vivo. Neuroscience 140, 623-633.

Johnson, S. W., and Wu, Y. N. (2004). Multiple mechanisms underlie burst firing in rat midbrain dopamine neurons in vitro. Brain Res. 1019, 293-296. (1976). Selective 6OHDAinduced destruction of mesolimbic (2006). Small-conductance $\mathrm{Ca}^{2+}$.

Kelly, P. H., and Iversen, S. D.

the explorative activity and methylphenidate hyperactivity - (CB) and methylphenidate stereotypy models (GS).

dopamine neurons: abolition of psychostimulant-induced locomotor activity in rats. Eur. J. Pharmacol. $40,45-56$

Köhler, M., Hirschberg, B., Bond, C. T., Kinzie, J. M., Marrion, N. V., Maylie, J., and Adelman, J. P. (1996). Small-conductance, calcium-activated potassium channels from mammalian brain. Science 273, 1709-1714

Koyama, S. (2004). Primer effects by conspecific odors in house mice: a new perspective in the study of primer effects on reproductive activities. Horm. Behav. 46, 303-310.

Kuczenski, R., and Segal, D. S. (1997). Effects of methylphenidate on extracellular dopamine, serotonin, and norepinephrine: comparison with amphetamine. J. Neurochem. 68 2032-2037.

Lacey, M. G., Mercuri, N. B., and North, R. A. (1987). Dopamine acts on D2 receptors to increase potassium conductance in neurones of the rat substantia nigra zona compacta. $J$. Physiol. (Lond.) 392, 397-416.

Ma, W., Miao, Z., and Novotny, M. V. (1999). Induction of estrus in grouped female mice (Mus domesticus) by synthetic analogues of preputial gland constituents. Chem. Senses 24, 289-293.

Pedarzani, P., Mosbacher, J., Rivard, A., Cingolani, L. A., Oliver, D., Stocker M., Adelman, J. P., and Fakler, B. (2001). Control of electrical activity in central neurons by modulating the gating of small conductance $\mathrm{Ca}^{2+}$-activated $\mathrm{K}^{+}$channels. J. Biol. Chem. 276, 9762-9769.

Peitersen, T., Hougaard, C., Jespersen, T., Jørgensen, N. K., Olesen, S. P., and Grunnet, M. (2006). Subtypespecific, bi-component inhibition of SK channels by low internal $\mathrm{pH}$. Biochem. Biophys. Res. Commun 343, 943-949.

Pucak, M. L., and Grace, A. A. (1996). Effects of haloperidol on the activity and membrane physiology of substantia nigra dopamine neurons recorded in vitro. Brain Res. 713 44-52.

Puopolo, M., Raviola, E., and Bean, B. P. (2007). Roles of subthreshold calcium current and sodium current in spontaneous firing of mouse midbrain dopamine neurons. J. Neurosci. 27, 645-656.

Randrup, A., Sørensen, G., and Kobayashi, M. (1988). Stereotyped behaviour in animals induced by stimulant drugs or by a restricted cage environment: relation to disintegrated behaviour, brain dopamine and psychiatric disease. Jpn. J. Psychopharmacol. 8, 313-327.

Sailer, C. A., Kaufmann, W. A., Marksteiner, J., and Knaus, H. G. (2004). Comparative immunohistochemical distribution of three smallconductance $\mathrm{Ca}^{2+}$-activated potassium channel subunits, SK1, SK2, and SK3 in mouse brain. Mol. Cell. Neurosci. 26, 458-469.

Sarpal, D., Koenig, J. I., Adelman, J. P., Brady, D., Prendeville, L. C., and Shepard, P. D. (2004). Regional distribution of SK3 mRNA-containing neurons in the adult and adolescent rat ventral midbrain and their relationship to dopaminecontaining cells. Synapse 53, 104-113.

Schultz, W. (2007). Behavioral dopamine signals. Trends Neurosci. 30, 203-210.

Shepard, P. D., and Bunney, B. S. (1988). Effects of apamin on the discharge properties of putative dopaminecontaining neurons in vitro. Brain Res. 463, 380-384.

Shi, W. X., Pun, C. L., and Zhou, Y. (2004). Psychostimulants induce low-frequency oscillations in the firing activity of dopamine neurons. Neuropsychopharmacology 29 , 2160-2167.

Stocker, M. (2004). $\mathrm{Ca}^{2+}$-activated $\mathrm{K}^{+}$ channels: molecular determinants and function of the SK family. Nat Rev. 5, 758-770

Strøbæk, D., Hougaard, C., Johansen, T. H., Sørensen, U. S., Nielsen, E. Ø., Nielsen, K. S., Taylor, R. D., Pedarzani, P., and Christophersen, P. (2006). Inhibitory gating modulation of small conductance $\mathrm{Ca}^{2+}$-activated $\mathrm{K}^{+}$channels by the synthetic compound (R)-N-(benzimidazol-2-yl)1,2,3,4-tetrahydro-1-naphtylamine (NS8593) reduces after hyperpolarizing current in hippocampal CA1 neurons. Mol. Pharmacol. 70, 1771-1782.

Vick, K. A., Guidi, M., and Stackman, R. W. (2010). In vivo pharmacological manipulation of small conductance $\mathrm{Ca}^{2+}$-activated $\mathrm{K}^{+}$channels influences motor behavior, object memory and fear conditioning. $\mathrm{Neu}$ ropharmacology 58, 650-659.

Waroux, O., Massotte, L., Alleva, L., Graulich, A., Thomas, E., Liégeois, J. F., Scuvée-Moreau, J., and Seutin, V. (2005). SK channels control the firing pattern of midbrain 
dopaminergic neurons in vivo. Eur. J. Neurosci. 22, 3111-3121.

Wolfart, J., Neuhoff, H., Franz, O., and Roeper, J. (2001). Differential expression of the small-conductance, calciumactivated potassium channel SK3 is critical for pacemaker control in dopaminergic midbrain neurons. J. Neurosci. 21, 3443-3456.

Wulff, H., Kolski-Andreaco, A., Sankaranarayanan, A., Sabatier, J. M., and Shakkottai, V. (2007). Modulators of small- and intermediate-conductance calciumactivated potassium channels and their therapeutic indications. Curr. Med. Chem. 14, 1437-1457.

Conflict of Interest Statement: The authors declare that the research was conducted in the absence of any commercial or financial relationships that could be construed as a potential conflict of interest.

Received: 20 December 2011; paper pending published: 12 January 2012; accepted:
19 January 2012; published online: 13 February 2012

Citation: Herrik KF, Redrobe JP, Holst $D$, Hougaard C, Sandager-Nielsen $K$, Nielsen AN, Ji H, Holst NM, Rasmussen $H B$, Nielsen EØ, Strøbok D, Shepard PD and Christophersen P (2012) CyPPA, a positive SK3/SK2 modulator, reduces activity of dopaminergic neurons, inhibits dopamine release, and counteracts hyperdopaminergic behaviors induced by methylphenidate. Front. Pharmacol. 3:11. doi: 10.3389/fphar.2012. 00011
This article was submitted to Frontiers in Neuropharmacology, a specialty of Frontiers in Pharmacology.

Copyright (c) 2012 Herrik, Redrobe, Holst, Hougaard, Sandager-Nielsen, Nielsen, Ji, Holst, Rasmussen, Nielsen, Strøbok, Shepard and Christophersen. This is an open-access article distributed under the terms of the Creative Commons Attribution Non Commercial License, which permits non-commercial use, distribution, and reproduction in other forums, provided the original authors and source are credited. 


\section{APPENDIX}

A

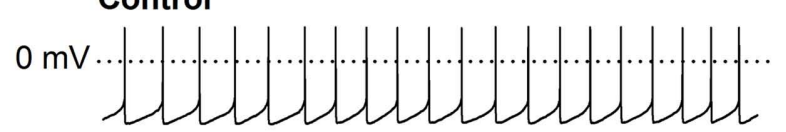
CyPPA

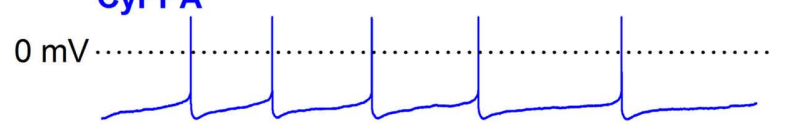

Wash

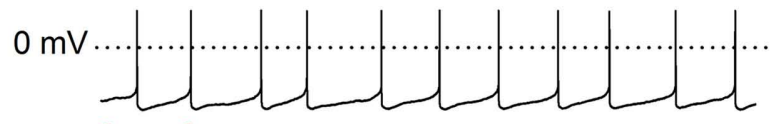

Apamin

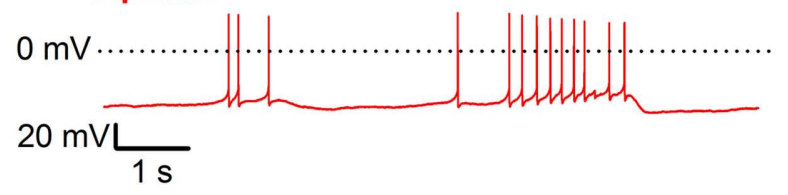

B

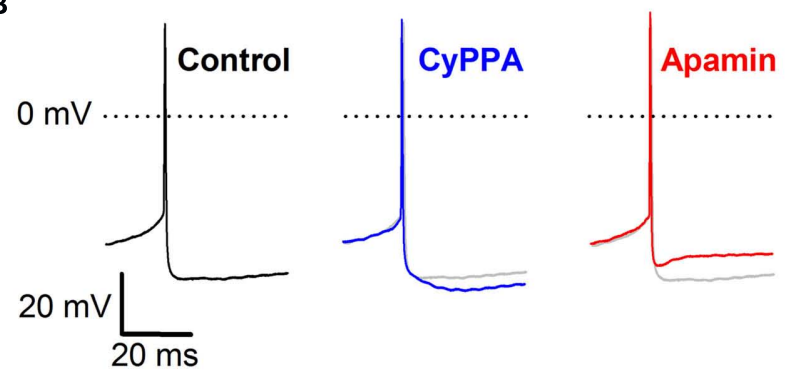

FIGURE A1 | CyPPA inhibits spontaneous activity via prolongation of the apamin-sensitive $\mathrm{mAHP}$ in SNc neurons in rat midbrain slices. (A) Typical pacemaker-like activity (upper panel) is altered by superfusion with $3 \mu \mathrm{M}$ CyPPA (second panel), which increases the mAHP and reduces spontaneous action potential firing, an effect that is reversed by prolonged washing (third panel). Apamin $(300 \mathrm{nM})$ reduces the mAHP and changes the firing pattern from pacemaker-like to bursting (lower panel). (B) Single spikes recorded in the absence of compound (control) or in the presence of $3 \mu \mathrm{M}$ CyPPA or $300 \mathrm{nM}$ apamin (control trace shown as dimmed for comparison). Note the prolongation of the mAHP by CyPPA and its block by apamin. 